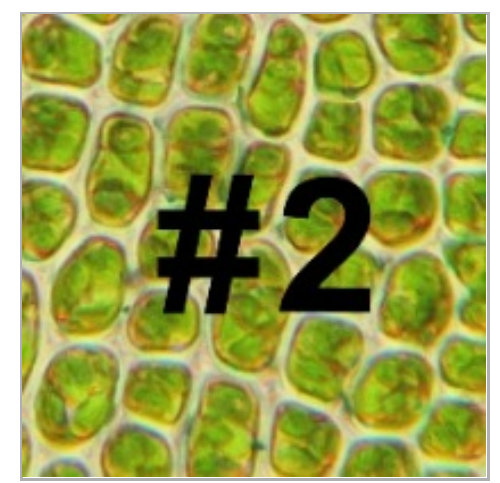

AUG 20, 2019

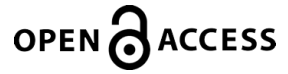

DOI:

dx.doi.org/10.17504/protocol s.io.4q4gvyw

Protocol Citation: Donald J. MacKenzie, Morven A.

McLean, Srima Mukerji, Margaret Green 2019. RNA Isolation from Plant Tissue Protocol 2: McKenzie et al's Qiagen hybrid method. protocols.io

https://dx.doi.org/10.17504/p rotocols.io.4q4gvyw

License: This is an open access protocol distributed under the terms of the Creative Commons Attribution License, which permits unrestricted use, distribution, and reproduction in any medium, provided the original author and source are credited

Protocol status: Working These protocols were used for RNA extraction from plant tissues in order to support the One Thousand Plants initiative's work to produce RNA-Seq transcriptomes from a diverse collection of plant samples.

Created: Jun 25, 2019

Last Modified: Aug 20, 2019

\section{(3) RNA Isolation from Plant Tissue Protocol 2: McKenzie et al's Qiagen hybrid method}

$\rightarrow$ In 1 collection

Donald J.

MacKenzie ${ }^{1}$, Morven A. McLean ${ }^{1}$, Srima Mukerji ${ }^{1}$, Margaret Green ${ }^{1}$

${ }^{1}$ Centre for Plant Health, Agriculture and Agri-Food Canada, 8801 East Saanich Road, Sidney, BC Canada V8L 1H3<smiles>C1CCCCCC1</smiles>

\section{Eric Carpenter}

\section{ABSTRACT}

Implemented by: Jim Leebens-Mack and Charlotte Carrigan

This protocol was developed by McKenzie et al. ${ }^{2}$ to facilitate the isolation of RNA from woody plants rich in phenolics and polysaccharides, such as grapes (Vitaceae) and fruit bearing Rosaceae (apples, cherries and pears). The protocol is provided on Qiagen's website as an alternative method to be used in combination with their RNeasy Plant Minikit. We repeat the protocol here in the event that this protocol is removed from Qiagen's website or readers find it difficult to obtain the original publication.

This protocol is part of a collection of eighteen protocols used to isolate total RNA from plant tissue. (RNA Isolation from Plant Tissue Collection: https://www.protocols.io/view/rna-isolation-from-plant-tissue-439gyr6)

2 McKenzie, D.J., McLean, M.A., Mukerji, S. \& Green, M. Improved RNA extraction from woody plants for the detection of viral pathogens by reverse transcriptionpolymerase chain reaction. Plant Disease 81, 222-226 (1997).

\section{ATTACHMENTS}

journal.pone.0050226.s01

$$
\text { 1.PDF }
$$


PROTOCOL integer ID:

25084

Keywords: RNA, RNA

isolation, RNA extraction,

woody plants, plant tissue
MATERIALS

MATERIALS

RNeasy Plant Mini Kit Qiagen Catalog

\#79904

\section{SAFETY WARNINGS}

(1) Please see SDS (Safety Data Sheet) for hazards and safety warnings.

1 Grind sample (up to $\triangle 50 \mathrm{mg}$ ) in liquid nitrogen to a fine powder using a mortar and pestle.

Note

Incomplete grinding of the starting material will lead to reduced RNA yields.

1.1 Transfer the tissue powder and liquid nitrogen to an appropriately sized tube, and allow the $\Delta$ liquid nitrogen to evaporate.

\section{Do not allow the sample to thaw.}

Continue immediately with step 2.

2 Add $\triangle 600 \mu \mathrm{L}$ lysis buffer to a maximum of $\triangle 50 \mathrm{mg}$ of tissue powder. Vortex vigorously.

3 Add $\triangle 60 \mu \mathrm{L}$ of $20 \%$ sarkosyl.

Note

For samples with a high starch content, incubation at elevated temperatures should be omitted to prevent swelling of the starting material.

3.1 Incubate at $88^{\circ} 70^{\circ} \mathrm{C}$ in a water bath or heating block for $\circlearrowleft 0: 10: 00$ with vigorous shaking or intermittent vortexing. 
4 Pipet the lysate directly onto a QIAshredder Spin Column (lilac-colored column, supplied in the RNeasy Plant Mini Kit) placed in a $2 \mathrm{ml}$ collection tube.

4.1 Centrifuge for $\circlearrowright 00: 02: 00$ at maximum speed $\left(>:_{\mathrm{g}}^{14000 \mathrm{x}}\right.$ [rcf]).

5 Carefully transfer the supernatant of the flow-through fraction to a new microcentrifuge tube without disturbing the cell-debris pellet in the collection tube.

Note

It may be necessary to cut the end off the pipet tip in order to pipet the lysate onto the QIAshredder Spin Column. Centrifugation through the QIAshredder Spin Column removes cell debris and simultaneously homogenizes the lysate. While most of the celldebris is retained on the QIAshredder Spin Column, a very small amount of cell debris will pass through and form a pellet in the collection tube. Be careful not to disturb this pellet while transferring the lysate to a new microcentrifuge tube.

6 Add 0.5 volumes (usually $\triangle 300 \mu \mathrm{L}$ ) ethanol (96-100\%), and mix well by pipetting. Note

If some lysate is lost during homogenization (step 4), reduce volume of ethanol proportionally. A precipitate may form after the addition of ethanol, but this will not affect the RNeasy procedure.

7 Continue with step 6 of the RNeasy Mini Protocol for Isolation of Total RNA from Plant Cells and Tissues and Filamentous Fungi in the RNeasy Mini Handbook. 


\section{Protocol}

NAME

RNA Isolation from Plant Tissue Protocol 6: pBIOZOL and Qiagen

RNeasy Plant Mini Kit Method

CREATED BY

Eric Carpenter

PREVIEW

7.1 Grind tissue to a powder in liquid nitrogen.

7.2 Add $\triangle 1.3 \mathrm{~mL}$ of cold $\left(8^{\circ} 4^{\circ} \mathrm{C}\right)$ pBIOZOL reagent for up to $\triangle 100 \mathrm{mg}$ of frozen ground tissue.

7.2.1 Mix by briefly vortexing or flicking the bottom of the tube until the sample is thoroughly resuspended.

7.3 Incubate the tube for 00:05:00 at 8 Room temperature

\section{Note}

Lay the tube down horizontally to maximize surface area during RNA extraction.

7.4 Centrifuge for $00: 10: 00$ at $\because \mathrm{g}^{12000 \mathrm{x}}$ in a microcentrifuge at $8^{\circ}$ Room temperature 
7.4.1 Transfer the supernatant to a new $\triangle 1.5 \mathrm{~mL}$ RNase-free tube.

7.5 Add \ $100 \mu \mathrm{L}$ of [M] 5 Molarity (M) $\mathrm{NaCl}$ and $\triangle 300 \mu \mathrm{L}$ chloroform.

7.5.1 Vortex vigorously.

7.6 Centrifuge at $\because g_{g}^{12000 x}$ for $00: 10: 00$

7.7 Transfer the top aqueous phase to a new $1.5 \mathrm{ml}$ RNase-free tube.

7.7.1 Add an equal volume of 5:1 acid phenol:chloroform to the tube.

7.8 Vortex the tube until the phases mix and appear cloudy.

7.8.1 Incubate at $8^{\circ} 20^{\circ} \mathrm{C}$ for $00: 05: 00$ 
7.9 Centrifuge at $\because{ }_{g}^{12000 x}$ for $00: 10: 00$

7.10 Transfer the top aqueous phase to a new $1.5 \mathrm{ml}$ RNase-free tube.

7.10.1 Add to the aqueous phase equal volume of 24:1 chloroform:isoamyl alcohol.

7.10.2 Vortex the tube until the phases mix and appear cloudy.

7.10.3 Then incubate at $\mathbb{8}^{\circ}$ Room temperature for 00:05:00

7.11 Centrifuge at $\because \mathrm{g}^{12000 \mathrm{x}}$ for $00: 10: 00$

7.12 Transfer the top aqueous phase to a new $1.5 \mathrm{ml}$ RNase-free tube.

7.12.1 Add $1 / 2$ volume of $100 \%$ ethanol.

7.13 Pour the contents of the tube into a Qiagen mini RNA spin column (pink), until the column 
is almost filled with liquid.

7.14 Cap the tube.

7.14.1 Centrifuge at $\because g_{g}^{12000 x}$ for $00: 00: 15$

Note

The column should be empty at the end of this spin.

7.15 Discard the flow-through from the collection tube.

7.16 Repeat the previous two steps with the same mini RNA spin column, until all of the liquid in the tube(s) has been passed through the column.

Note

The nucleic acid is now bound to the silica membrane in the spin column.

7.17 Apply ஃ $700 \mu \mathrm{L}$ of solution RW1 to the spin column.

7.18 Cap the tube. 
7.18.1 Centrifuge at $\because \mathrm{g}_{\mathrm{g}}^{12000 \mathrm{x}}$ for $00: 00: 15$

Note

The column should be empty at the end of this spin.

7.19 Discard the flow-through from the collection tube.

7.20 Apply $\triangle 500 \mu \mathrm{L}$ of solution RPE to the spin column.

7.20.1 Cap the tube

7.20.2 Centrifuge at $\because g_{g}^{12000 x}$ for $00: 00: 15$.

Note

The column should be empty at the end of this spin.

7.21 Discard the flow-through. 
7.22 Repeat previous two steps one time. E go to step \#7.20.2

7.23 Spin at maximum speed for 00:02:00 to remove remaining liquid from the silica membrane.

7.24 Transfer the spin column to a new $1.5 \mathrm{ml}$ conical bottom microcentrifuge tube.

7.25 Add $\triangle 30 \mu \mathrm{L}-\triangle 50 \mu \mathrm{L}$ of RNase-free water to the column.

7.25.1 Then let tube incubate at $8^{\circ} 20^{\circ} \mathrm{C}$ for 00:03:00

7.26 Spin at maximum speed for 00:01:00 to collect RNA solution. 